\title{
Management of Gastric Varices
}

\author{
Akio Matsumoto
}

Published online: 11 August 2011

(C) Springer Science+Business Media, LLC and the Cardiovascular and Interventional Radiological Society of Europe (CIRSE) 2011

I recently read with great interest the article by d'Othee et al. The authors treated gastric varices in the patient with partial splenic and portal thrombs by balloon-occluded retrograde transvenous obliteration (B-RTO) [1]. The patient had remarkable splenomegaly and thrombocytopenia, so congestion of the splenic vein seemed to have existed before B-RTO. Worsening of esophageal varices after B-RTO is thought to be due to the increase of blood flow in the branch of splenic vein (e.g., left gastric vein). B-RTO followed by partial splenic embolization [2, 3] might prevent the rupture of esophageal varices and performance of transjugular intrahepatic portosystemic shunting by the suppression of the increase of the blood flow in splenic vein. The efficacy of B-RTO in patients with an advanced liver disease (e.g., Child-Pugh classification C) is unclear [4]. The present patient had a very small liver. What was the patient's Child-Pugh score? Performance of Doppler ultrasonography could reveal the change of blood flow in splenic vein before and after B-RTO as well as after ligation of esophageal varices.

Conflict of interest No conflict of interest.

\section{References}

1. Janne d'Othee B, Walker TG, Marota JJ et al (2011) Splenic venous congestion after balloon-occluded retrograde transvenous obliteration of gastric varices. Cardiovasc Intervent Radiol 9. doi: 10.1007/s00270-011-0160-8

2. Ferral H (2008) Balloon-occluded retrograde transvenous occlusion. Tech Vasc Intervent Rad 11:225-229

3. Matsumoto A, Takimoto K (2006) Gastric fundal varices: new aspects of nonsurgical treatment in Japan. Nat Clin Prac Gastroenterol Hepatol 3:4-5

4. Ninoi T, Nishida N, Kaminou T et al (2004) Balloon-occluded retrograde transvenous obliteration of gastric varices with gastrorenal shunt: long-term follow-up in 78 patients. Am J Roentgenol 184:1340-1346

\footnotetext{
A. Matsumoto $(\square)$

Department of Internal Medicine, Kumiyama Minami Hospital,

28 Boumuranaka, Bounoike, Kumiyama-cho, Kuze-gun,

Kyoto 613-0042, Japan

e-mail: marsh@hkg.odn.ne.jp
} 